\title{
Precision Farming and Predictive Analytics in Agriculture Context
}

\author{
Srinath.Yasam, S Anu H Nair
}

\begin{abstract}
The scope of sensor networks and the Internet of Things spanning rapidly to diversified domains but not limited to sports, health, and business trading. In recent past, the sensors and MEMS integrated Internet of Things are playing crucial role in diversified farming strategies like dairy farming, animal farming, and agriculture farming. The usage of sensors and IoT technologies in farming are coined in contemporary literature as smart farming or precision farming. At its early stage of smart farming, the practices applying in agriculture farming are limited to collect the data related to the context of farming, such as soil state, weather state, weed state, crop quality, and seed quality. These collections are to help the farmers, scientists to conclude the positive and negative factors of crop to initiate the required agricultural practices. However, the impact of these practices taken by the agriculturists depends on their experience. In this regard, the computer-aided predictive analytics by machine learning and big data strategies are having inevitable scope. The emphasis of this manuscript is reviewing the existing set of computer-aided methods of predictive analytics defined in related to precision farming, gaining insights into how distinct set of precision farming inputs are supporting the predictive analytics to help farming communities towards improvisation. It is imperative from the review of the literature that right from the farming process and techniques to usage of distinct sets of farming precision models like the machine learning solutions and other such factors indicate that there are potential ways in which the precision farming solutions can be resourceful for the farming groups. Optical sensing, soil analysis, imagery processing based analysis, machine learning models that can support in effective prediction are some of the key areas wherein the numbers of solutions that have offered from the market are high. From the compiled sources of literature in the study, there must be many techniques, tools, and available solutions, but one of the key areas wherein the solutions are turning complex for the companies is about usage of the comprehensive kind of machine learning models used in the precision farming which is currently a major gap and is potential scope for the future research process. This contemporary review indicating that both supervised and unsupervised machine learning models are yielding results, still in terms of improvements that are essential in precision farming. The overall efforts of this review portraying that, there is a need for developing a system that can self-train on the critical features based on the loop model of features gathered from the process and make use of such inputs for analysis. If such clustered solution is gathered, it can help in improving the quality of analysis based on the learning practices and the historical data captured from the systems aligned.
\end{abstract}

Keywords: Precision agriculture, optical sensors, Variable Rate Fertilizers, Global Positioning System, Geographic Information System.

Revised Manuscript Received on December 15, 2019.

Mr. Srinath.Yasam, Research Scholar, Annamalai University, Email: srinath.yasam@gmail.com

Dr. S Anu H Nair, Assistant Professor, Department of Computer Science \& Engg, Faculty of Engineering and Technology, Annamalai University, (Deputed to WPT, Chennai), Email: anu_jul@yahoo.co.in

\section{INTRODUCTION}

India is regarded as one of the most progressive nations, having a population of over one billion. At the same time, it is generally regarded as one of the fastest flourishing economies across the globe. From the nation's big population, it can generally note that about 58.4 percent are local agriculturalists. Despite the fact that the achievements of the nation when it comes to crop yields have been highly remarkable, they are merely 30 per cent to 60 per cent of the best crop yields that can be attained in the same farms within the nations that are developed, as well as in the nations which are still developing as demonstrated by the study that was done by [1]. Currently, the country is ranked second globally with regards to farm output. Agriculture together with the other allied industries was accounting for 13 percent of the aggregate GDP during the year 2014, approximately 50 percent of the whole workforce. When it comes to topography, agriculture is the widest economic industry. It is playing a figurative role in a wide-ranging socio-economic environment of India. While this is the case, there have been various kinds of reports, which indicate that the agricultural sector within the nation is performing as per expectations [1]. There has been a general decline in the contribution of agriculture to the GDP of India the same way there has been a decline in the economic growth of the country. Precision agriculture (PA) refers to the farming management approach, which is mainly founded on observation, measurement, and ensuring that there are proper responses to the inter as well as the intra-field variability within the crops. Crop variability generally has a spatial, as well as a temporal element that generally complicates the statistical or the computational treatments [1]. Various agricultural specialists have noted the need to incorporate sensor data in various agricultural systems and also the need to actualize ways of overcoming the realistic propositions, which involves the government, as well as its policies. The data analysts, agricultural experts as well as the others who adopt this technology have always provided ways of bringing about better culmination at reduced costs. The widespread progression and advancement of data in the last decades have contributed to a unique realm in the sphere of IT as well as data science, which is referred to as the Big Data. The highly resourceful technology has gained intensified consideration as one of the key measures, which can be adopted in order to ensure that there is an improvement in the functioning of the agricultural systems through the combination of diverse systems through a data, as well as a communications platform that have the abilities to lessen unnecessary crop failures, improve and fasten agricultural governing besides enabling passage to every aspect of the agricultural services for various circumstances.

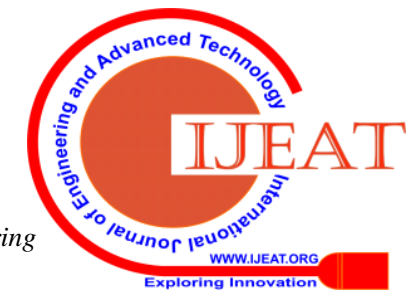




\section{Precision Farming and Predictive Analytics in Agriculture Context}

It collects all the feasible crop information, which has produced via smart electronic devices (such as electromagnetic sensors, moisture sensors, as well as optical sensors) for a detailed region. The smart devices are capable of generating prodigious quantities of information, compelled by proper record keeping, compliance as well as regulatory compliance that are associated with the big data. PA entails collection of real-time, as well as traditionally produced data in organized and amorphous datasets. Due to the fact that PA generates more data, which are generally unstructured, present research strives to establish highly useful data out of them [2]. In the future, there is need for an improvement in the overall quality of the agricultural services and products, which have produced a drastic reduction in the investment costs. Big data can support a wide array of PA activities through the discovery of insights as well as intelligence from data to address numerous new and significant farming decisions and challenges. Within the agricultural industry, information and communication technology is playing a highly significant role in the provision of newer tools and techniques that can be used to generate data, to transform the data generated, and to ensure effective management of the given data [3]. Newer technologies offer a framework that can be used to gain insights from the data obtained to provide information that can employ for improving productivity and eliminating unnecessary investments well in advance. In agricultural settings, it is worth pointing out that big data is the huge quantities of data, which have produced in the agricultural settings. It is always a big challenge to process and to ensure that there is effective management of the big data, which is generated in the agricultural settings. Big data tools and techniques ensure that there is a change in this. The traditional methodologies, as well as platforms, were not highly effective in ensuring that this is done.

The processing of big volumes of data requires newer hardware, as well as newer software platforms that have highly effective tools. In particular, it is worth pointing out that PA datasets always have data, which is linked to crop rotations, crop patterns, weather patterns, the conditions of the environment, the types of soil, soil nutrients, Geographic Information System (GIS) data, farmer details, Global Positioning System (GPS) data, agriculture machinery data, like yield monitoring as well as Variable Rate Fertilizers (VRF) [2].

The scholars who work in this domain have the chance to discover knowledge from big data. Big data analytics can ensure that relationships have discovered, and also that patterns are established based on the data that is acquired. It is also worth pointing out that big data can offer solutions to numerous agricultural aspects. For instance, it can improve the process of decision-making, enable extraction of newer insights besides offering information concerning the manner in which future farming should be done. ICT also offers data to those who are engaged in farming via mobile applications, SMS services, and agriculture knowledge hubs besides helping the farmers to develop various web applications. The ICT contributes to PA through remote sensing like GIS, GPS, devices as well as data monitors. In addition, ICT is playing a major role as it ensures that data is transmitted remotely. It also ensures that data is managed remotely.

\section{STATE OF ART}

Online trading applications used in the Indian agricultural sector: State, Andhra Pradesh has generally referred to as India's rice bowl. This generally indicates that there is a dire need for proper work to be done with sound computational techniques. Andhra Pradesh has been at the front of technology-oriented change within the agricultural sector. It has constant unwavering agricultural objectives in Sunrise Andhra Pradesh Vision 2029. On the same note, AP AgTech Summit of the year 2017 [4] was also in agreement for sophistication in a manner that for every global leader and business CEOs, those starting start-ups, the main policymakers, as well as big ICT experts to discuss highly advanced concepts to transform agriculture. In the recent past, some of the main authorities have commenced a smartphone-oriented application for the diagnosis of plants within the Telugu region in partnership with the ICRISAT.

Agriculture Department has widely adopted predictive analytics depending on the satellite information with the aim of forecasting water-stressed farms crops-wise with the sole aim of offering productive irrigation via rain guns. At the same time, a different technology program was commenced in the past year, which mainly aimed to offer support to rain-fed farmers. M-trading makes the small, as well as the marginal farmers, to be in a position to ensure that their fresh products are sold straight to various businesses all through the nation through the use of the smartphone.

\subsection{A New Age of Agriculture using Big Data}

In order to ensure that there is an overall improvement in the level of efficiency in the whole agricultural value chain through ensuring financial inclusion of farmers via datadriven intuitions, enhancing the level of effectiveness of the marketplace, as well as the supply-chain for various Agri input traders, producers, as well as policymakers, there is the dire need for various kinds of measures to be put in place to ensure that there are exclusive risk management strategies, which adopt multi-sensor data, like IoT, satellites, as well as drones. On the same note, there is the need for adoption of artificial intelligence algorithms to derive actionable intelligence. Besides, there is a need for the use of highly refined agricultural digital inputs for the farmers with the sole aim of procuring a wide array of quality inputs, which are ranging from soil-seed-sale. The usage of digitized records concerning the farming practices demonstrates a highly significant aspect when it comes to the documentation of the different kinds of strategies, which can employ for figuring out the aspects of given sale. Due to this, global companies are highly significant when it comes to fresh budding trade crops for incorporation into the overall supply chain. In this aspect, it is worth pointing out that PA has been regarded to be a major aspect in the nations, which are highly developed, and in which automation is the order of the day. A number of things are automated, and this is crucial. 


\subsection{Model-Driven Answers for Agricultural challenges}

The main scientific research institute in the United States is the Agricultural Research Service (ARS) [5]. The major concern of the ARS is to assess the kinds of food that is eaten in the nation, to evaluate the kind of water that is drunk, and also to ensure proper evaluation of the air that the individuals breathe in the nation. This is mainly aimed at ensuring that they are of high quality. It also directs countrywide, as well as zone agri-business, which are its major concerns.

The main work of the ARS is to carry out different kinds of research, with the sole aim of increasing and providing different types of solutions to the main agricultural challenges, which are faced. At the same time, they also provide statistics, which can be used as a basis for decision-making by the players. One of the main visions of ARS is to make sure that the United States is pushed towards roper research in agriculture and also to ensure that there are highly accurate statistics. Research programs carried out through ARS' Crop Production and Protection Program (CPP) across the nation is capable of offering science-oriented data, as well as technologies that can employ for fulfilling or for booming crop production. The application of highly effective Big Data Analytics techniques for increasing the level of crop productivity, as well as the level of excellence generally include:

- The application of highly suitable crop control tools for innovative, as well as for the conventional crops, which are preserving natural resources;

- Proper organization of integrated control tools for different kinds of pests;

- Automation of various control activities for handling labor constraints; and

- Having in place highly developed crop control models, as well as choice aids.

The impacts of the conditions of the environment on agriculture always result in results, which are contradictory at different locations due to the fact that various kinds of factors like soil, crop, water, climate, and weather as well as management dissimilarities. Hence, to ensure that there is a proper analysis of the outcomes, Big Data tools, which make the researchers be in a position to explore newer discoveries for using Big Data techniques for the fortification of the local best methodologies for forecasting the conditions of the climate and weather with various agroclimatic conditions.

\section{Challenges}

The hindrances for Big Data, as well as Smart Farming that is well detailed in the previous studies may roughly categorize into technical challenges as well as organizational challenges. The organizational challenges are generally regarded to be the most significant [6], [7]. Additionally, solution can provide to a number of the technical problems that are always faced when adequate business opportunities for Big Data in Smart Farming have formed. As a result, there should be clear ROI, as noted by the work that was done by [8]. On the side of the revenue, there is a big challenge of making sure that the solutions can be afforded by the farmers, mainly for the nations that are still developing [9]. When there are generally more people using Big Data applications, highly valuable data can always be obtained. This is always called the reciprocal value of Big Data [10]. It is a highly significant aspect, which ought to be implemented carefully in the strategies which firms use. When the costs have taken into consideration, the other major hindrance entails automation of data acquisition in a manner that there are practically no costs as demonstrated in work done by [7]. Due to the fact that on-farm data shall still be under the control of individual firms, investments have required within a collective pool infrastructure for transferring and for integrating data and ultimately making applications through it. In the work that was done by [11], this is referred to as Agricultural Business Collaboration as well as Data Exchange Facilities (ABCDEFs). A significant concern about the ABCDEFs is whether they shall be closed, proprietary systems like presently Monsanto's Field Scripts, or whether these shall be very open as suggested by e.g. the Open ATK or the FI space program. Ultimately, the other business-linked problem that is faced when it comes to Big Data entails assessing the manner in which the probability of information across food systems may be used [7].

One of the greatest problems that are faced when it comes to Big Data governance entails assessing the manner in which security, as well as privacy, can be maintained [8], [6], [7], [10]. Presently, in some cases, it inhibits developments if the data occurs in silos, protected by the employees or firms as a result of this concern. They fear that the data might get into the wrong hands (like the rivals) [12]. Therefore, confidential and restricted access to Big Data, as well as ensuring that trust is built with the farmers ought to be a starting point when the applications are being developed [10]. Hence, newer organizational linkages as well as newer approaches to cooperation ought to establish within the agri-food chain [7]. Put in a simple manner, it generally implies the capacity to rapidly access the right sources of data to assess the key performance or the core processes, as well as outcome indicators when highly successful strategies are being built [13].

These hindrances, which have been pointed out above, have resulted in the underutilization of the current quantities of farm data [14]. The other key challenge is the fact that the quality, as well as the availability of the data is always very poor and ought to be taken into consideration prior to being used [8], [6]. At the same time, the lack of integration has also been reported to be one of the main problems, which is being faced [13]. Anonymization of data in order to make sure that the given data cannot be tracked back into individual firms may also be a major challenge in some instances [6]. At the same time, there are various attempts to have in place more open governmental data (cf the GODAN initiative). However, the challenge may be the fact that the fundamental systems were generally not made for that, or they might be containing numerous data that may not be consistent or not compatible as demonstrated by the work done by [6]. 


\section{Precision Farming and Predictive Analytics in Agriculture Context}

\section{GAP ANALYSIS}

Precision farming as a solution has evolved over a period, and there are phenomenal conditions that are emphasizing on how the conditions that could support in improving the conditions of farming. Right from usage of the robotics in monitoring and sensors to interventional process of analyzing the quality of farming, usage of the resources in optimal conditions, multiple factors are impacting the conditions that are driving the precision farming conditions [15].

Deep learning and the machine learning model that was proposed in many of the studies reviewed in this review paper has significant importance and has been addressing one or the other set of imperative constraints. However, there are conditions wherein the discussed set of deep learning or the machine learning models in combination with the systematic big data solutions has certain constraints [16], [17], [18].

In lines of pragmatic farming conditions, the scope for farming a specific set of crops are highly dependent on various factors that impact its seedling, lead time for the crop, and how the yield is managed. Right from weather to the ground conditions, seed conditions, the techniques of crop plantation and the watering conditions, and many other such dozens of factors impact the quality and the yield [19].

Some of the key areas wherein the precision farming has made profound use of technology systems and developments Table 2 are

Table 1: Review of various precision farming areas

\begin{tabular}{|c|c|c|c|}
\hline $\begin{array}{l}\text { Evolved } \\
\text { Solutions }\end{array}$ & Areas of Implementation & 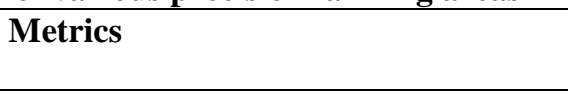 & Application Tools \\
\hline $\begin{array}{l}\text { Infrastructure } \\
\text { solution }\end{array}$ & $\begin{array}{l}\text { Farm sensors for farmland } \\
\text { monitoring regarding security } \\
\text { etc. }\end{array}$ & $\begin{array}{l}\text { Towards monitoring any intrusion in } \\
\text { the remote farming conditions }\end{array}$ & $\begin{array}{ll}- & \text { GPS } \\
- & \text { GIS } \\
- & \text { VRT } \\
\text { - } & \text { Spatial Variability of } \\
& \text { Hydraulic } \\
& \text { Conductivity } \\
\end{array}$ \\
\hline Sensors & $\begin{array}{l}\text { Weather Prediction towards } \\
\text { the field locations } \\
\text { Thermal images of the } \\
\text { farming locations to } \\
\text { understand the changing } \\
\text { parameters } \\
\text { Combination of the big data } \\
\text { inputs from multiple } \\
\text { parameters like the weather } \\
\text { prediction reports etc. } \\
\text { Inputs in the form of } \\
\text { developing an ecosystem of } \\
\text { collecting various inputs that } \\
\text { can be garnered based on the } \\
\text { sensors. }\end{array}$ & $\begin{array}{l}\text { Height and density of the soil, water } \\
\text { levels in the soil, characteristics of the } \\
\text { soil, weather conditions, information } \\
\text { on the grazing scope, related } \\
\text { topological conditions, etc. were } \\
\text { investigated. } \\
\text { For identifying the inputs in the farm } \\
\text { conditions, which are transmitted to the } \\
\text { central analysis system. } \\
\text { Normalized vegetation index (NDVI) }\end{array}$ & $\begin{array}{l}\text { - Ground sensors, } \\
\text { field sensors with } \\
\text { IoT integration, } \\
\text { - Unmanned Aerial } \\
\text { Surveillance (UAS) }\end{array}$ \\
\hline $\begin{array}{l}\text { Weather } \\
\text { Prediction using } \\
\text { Big data }\end{array}$ & $\begin{array}{l}\text { To have more accurate levels } \\
\text { of prediction of weather } \\
\text { conditions to suit the farming } \\
\text { conditions }\end{array}$ & $\begin{array}{l}\text { Farming Decision support } \\
\text { Increasing efficiency } \\
\text { Water and other resources management }\end{array}$ & $\begin{array}{ll}\text { - } & \begin{array}{l}\text { Regression } \\
\text { Coefficients, }\end{array} \\
\text { - } & \begin{array}{l}\text { Supervised and non- } \\
\text { supervised learning } \\
\text { models }\end{array} \\
\text { - } & \text { Linear regression } \\
\text { - Map Reduce } & \begin{array}{l}\text { Algorithms } \\
\text { Algition }\end{array} \\
\end{array}$ \\
\hline $\begin{array}{l}\text { Weed } \\
\text { detections }\end{array}$ & Image sensoria's & Detection of the weed conditions & $\begin{array}{ll}\text { - } & \text { Feature selection } \\
\text { - } & \text { Feature } \\
\text { combinations } \\
\text { - Optimal Classifiers } \\
\text { usage. }\end{array}$ \\
\hline
\end{tabular}




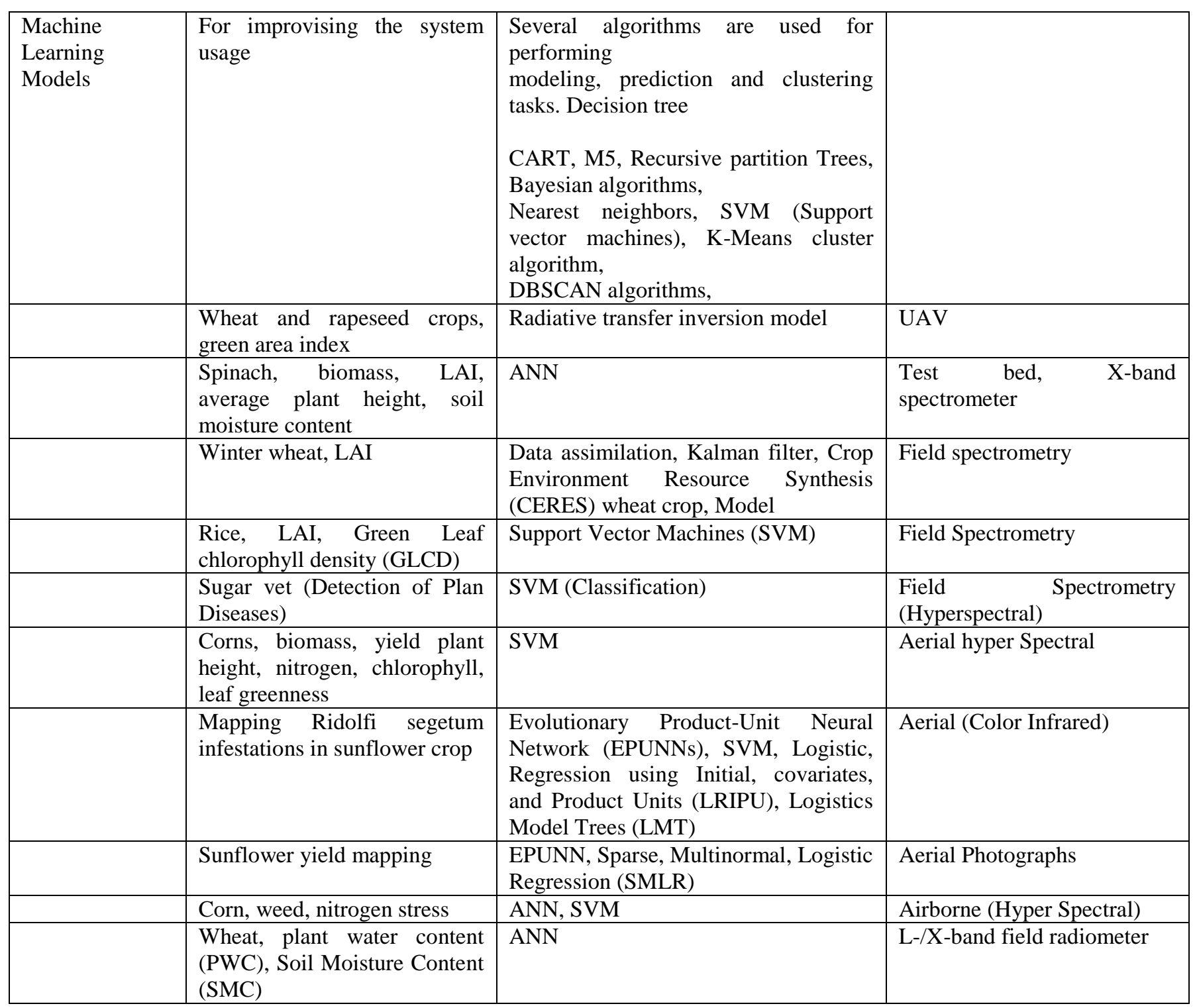

Taking such factors into account, it is imperative that there is integral need for the more contemporary and robust kind of models of machine learning that can substantiate the efforts of precision farming. There is need for developing a system that can self-train on the critical features based on the loop model of features gathered from the process and make use of such inputs for analysis. If such clustered solution has gathered, it can help in improving the quality of analysis based on the learning practices and the historical data captured from the systems aligned.

It is imperative from the analysis that there are certain critical factors in every set of development like focusing on the features that play a critical role. For instance, in the process flow chart depicted in Figure 3 reflects on the potential ways in which the research study [20] has focused on the usage of the map-reduce algorithm model for the weather prediction conditions. It is imperative that though the structure is formidable, unless there are profound set of developments in the domain, in terms of effective ways of feature selection, it could be very challenging for gathering potential outcomes from the process.

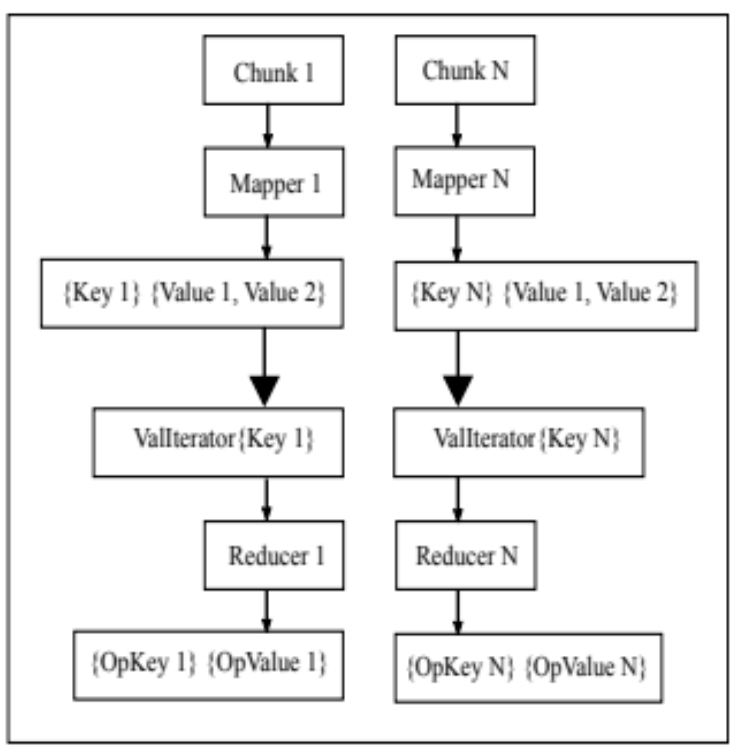

Figure 1: Map Reduce Algorithm for Weather Selection [20] 


\section{Precision Farming and Predictive Analytics in Agriculture Context}

Figure 4 mentioned below is discussed in the research study [21] as the potential model towards discussion of weed selection using random forest machine learning algorithm combined with hyperspectral imagery conditions. From the process depicted in the model and the subsequent results that have concluded, it is evident that the model can generate outcome. But the categorical condition of feature selections based on the inputs available like the NDVI and the RVI turns to be a critical factor. If there are certain sets of feature optimizations for better combinations, depending on the conditional aspects of farming and the nature of product for farming, there can be more effective performance delivery in the system.

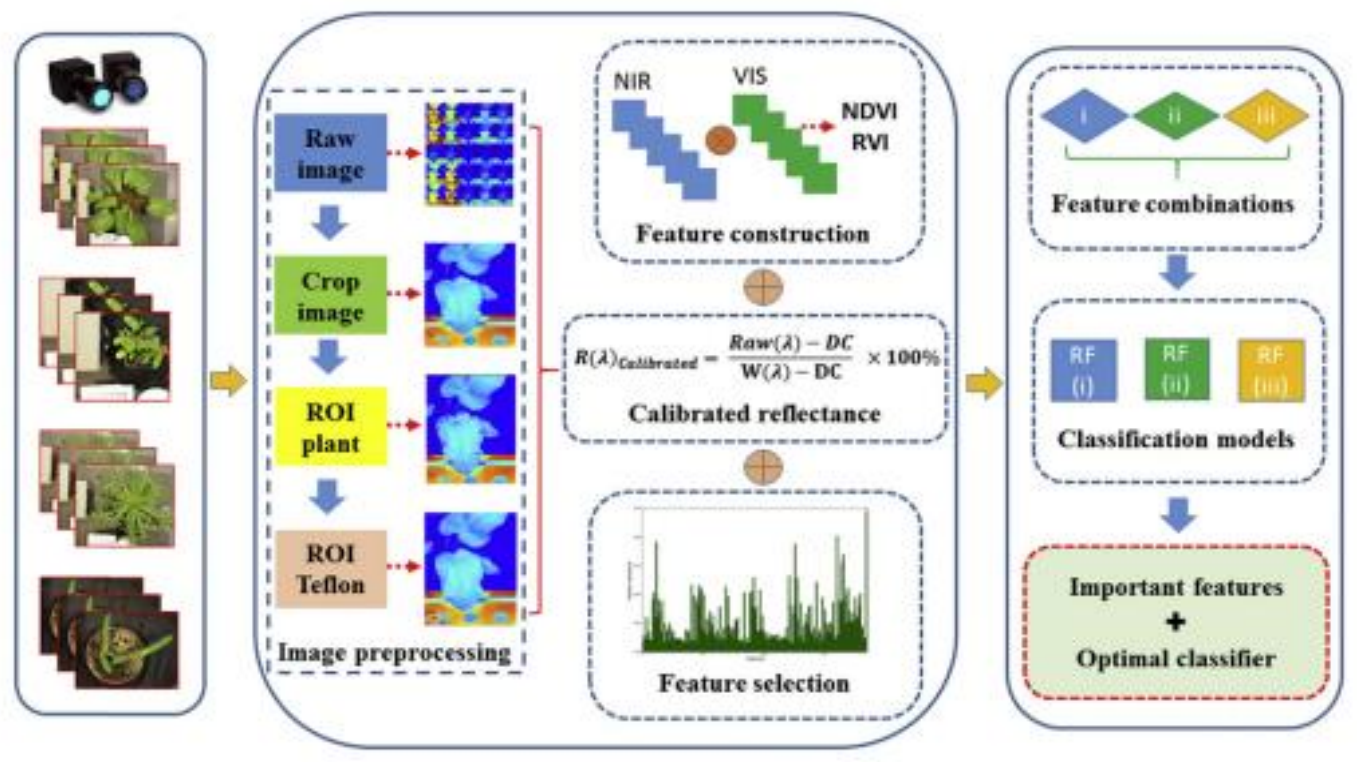

Figure 2: Weed selection process [21]

In an illustrative scenario, the machine learning model to be implemented should understand the features that should be chosen for analysis, have weighted average for each of the features, for every kind of crop or geographic or the farming culture, which could consider as attribute selection. If such integrated machine learning model could develop, it can lead to sustainable solution development in precision farming conditions.

\section{FUTURE RESEARCH OBJECTIVES}

- To understand the various attributional features for the precision farming conditions and develop a framework for weighted averaging the features

- To develop machine learning models that can support in holistic feature selection-based analysis of the data and support in more accurate condition of precision farming conditions.

- To develop interventional process of the machine learning model, that can take into account lifecycle stage of a crop and support in real-time precision farming analysis.

\section{CONCLUSION}

In terms of conclusion from the reviewed literature, it is evident that the processes of precision farming have evolved over period of time and there are phenomenal developments that are being envisaged in the domain. Categorically in the case of embracing big data kinds of solutions, the role of machine learning models for predictive analytic process for precision farming is turning to be an integral need. It is very important to focus on the developments in the domain in region-specific facet, as at times the issue of digital divide too might have significant impact on how the precision

farming solutions available are being used and the scope for implementation of the new solutions infrastructure feasibility, and affordability towards implementation of the solution. From the review of some of the machine learningbased precision farming solutions that have discussed in the domain, it is evident that there is need for more comprehensive solutions towards embracing the machine learning models. Some of the existing models though are delivering results in the predictive levels for precision farming, still the accuracy levels in the system implementation can be more widespread if there is a holistic kind of machine learning model developed, which can help the teams in effective and accurate analysis of the systems, solutions and the farming life cycle conditions that have used as integral to precision farming conditions.

\section{REFERENCES}

1. http://en.wikipedia.org/wiki/Agriculture_in_India

2. R. D. Grisso, M. M. Alley, P. McClellan, D. E. Brann, and S. J. Donohue, "Precision farming. a comprehensive approach," 2009.

3. R. D. Ludena, A. Ahrary et al., "Big data approach in an ict agriculture project," in Awareness Science and Technology and UbiMedia Computing (iCAST-UMEDIA), 2013 International Joint Conference on. IEEE, 2013, pp. 261-265.

4. AP Ag-Tech Summit 2017: Progressive Farmer, Smart Farming, 1517 Nov, 2017, Vizag, www.apagtechsummit2017.in/.

5. ARS within USDA - Annual Report on Science, http://www.ars.usda.gov/.

6. Orts, E., Spigonardo, J., 2014. Sustainability in the Age of Big Data. IGEL/Wharton, University of Pennsylvania, Pennsylvania, US, p. 16.

7. Sonka, S., 2015. Big Data: from hype to agricultural tool. Farm Policy Journal 12, 1-9.

8. Lesser, A., 2014. Big Data and Big Agriculture. Gigaom Research, p. 11. 
9. Kshetri, N., 2014. The emerging role of Big Data in key development issues: opportunities, challenges, and concerns. Big Data \& Society 1

10. Van 't Spijker, A., 2014. The New Oil - Using Innovative Business Models to Turn Data into Profit. Technics Publications, Basking Ridge.

11. Poppe, K.J., Wolfert, J., Verdouw, C.N., Renwick, A., 2015. A European perspective on the economics of Big Data. Farm Policy Journal 12, 11-19

12. Gilpin, L., 2015b. How Big Data Is Going to Help Feed Nine Billion People by 2050. TechRepublic. http://www.techrepublic.com/article/how-big-data-is-going-tohelpfeed-9-billion-people-by-2050/ (Accessed: 7 May 2015).

13. Yang, C., 2014. Big Data and its potential applications on agricultural production. Crop, Environment \& Bioinformatics 11, $51-56$

14. Bennett, J.M., 2015. Agricultural Big Data: utilization to discover the unknown and instigate practice change. Farm Policy Journal 12, 43-50.

15. Wolfert, Sjaak, Lan Ge, Cor Verdouw, and Marc-Jeroen Bogaardt "Big data in smart farming-a review." Agricultural Systems 153 (2017): 69-80

16. Zhang, Naiqian, Maohua Wang, and Ning Wang. "Precision agriculture a worldwide overview." Computers and electronics in agriculture 36, no. 2-3 (2002): 113-132.

17. Tiwari, Akhilesh, and Praveen Kumar Jaga. "Precision farming in India A review." Outlook on Agriculture 41, no. 2 (2012): 139-143.

18. Singh, N. P. "Application of Data Warehouse and Big Data Technology in Agriculture in India." In Proceedings of VII Seventh International Conference on Agricultural Statistics, Rome, October, pp. 24-26. 2017.

19. Takeshima, Hiroyuki, and Pramod Kumar Joshi. Protected agriculture, precision agriculture, and vertical farming: Brief reviews of issues in the literature focusing on the developing region in Asia. Vol. 1814. Intl Food Policy Res Inst, 2019.

20. Bendre, M. R., R. C. Thool, and V. R. Thool. "Big data in precision agriculture: Weather forecasting for future farming." In 2015 1st International Conference on Next Generation Computing Technologies (NGCT), pp. 744-750. IEEE, 2015.

21. Morota, Gota, Ricardo V. Ventura, Fabyano F. Silva, Masanori Koyama, and Samodha C. Fernando. "Big Data Analytics and Precision Animal Agriculture Symposium: Machine learning and data mining advance predictive big data analysis in precision anima agriculture." Journal of animal science 96, no. 4 (2018): 1540-1550. 